\title{
1 Live biotherapeutic throat spray for respiratory virus inhibition and interferon pathway induction
}

2 Authors: Irina Spacova ${ }^{1 *}$, Ilke De Boeck ${ }^{1 *}$, Eline Cauwenberghs ${ }^{1}$, Lize Delanghe ${ }^{1}$, Peter A. Bron ${ }^{1}$, Tim 3 Henkens $^{2}$, Alix Simons², Imane Gamgami², Leentje Persoons ${ }^{3}$, Ingmar Claes², Marianne F. L. van den Broek $^{1}$, Dominique Schols ${ }^{3}$, Peter Delputte ${ }^{4}$, Samuel Coenen ${ }^{5,6}$, Veronique Verhoeven $^{5}$, Sarah Lebeer ${ }^{1 \$}$

${ }^{1}$ Research Group Environmental Ecology and Applied Microbiology, Department of Bioscience Engineering, University of Hygiene, Department of Biomedical Sciences, University of Antwerp, Belgium. ${ }^{5}$ Family Medicine and Population Health (FAMPOP), University of Antwerp, Antwerp, Belgium. ${ }^{6}$ Vaccine \& Infectious Disease Institute (VAXINFECTIO), University of Antwerp, Antwerp, Belgium.

*Irina Spacova and Ilke De Boeck contributed equally to this work \$corresponding authors Irina.Spacova@uantwerpen.be and Sarah.Lebeer@uantwerpen.be

\section{Abstract}

Respiratory viruses such as influenza viruses, respiratory syncytial virus (RSV), and coronaviruses initiate infection at the mucosal surfaces of the upper respiratory tract (URT), where the resident respiratory microbiome has an important gatekeeper function. In contrast to gut-targeting administration of beneficial bacteria against respiratory viral disease, topical URT administration of probiotics is currently underexplored, especially for the prevention and/or treatment of viral infections. Here, we report the selection and formulation of a broad-acting throat spray with live lactobacilli which induce interferon regulatory pathways and are able to inhibit respiratory viruses. Rational selection of Lactobacillaceae strains was based on safety, applicability, and potential antiviral and immunostimulatory efficacy in the URT. Three strains, Lacticaseibacillus casei AMBR2, Lacticaseibacillus rhamnosus GG and Lactiplantibacillus plantarum WCFS1 significantly reduced the cytopathogenic effects of RSV, influenza A/H1N1 and B viruses, and HCoV-229E coronavirus in coculture models with bacteria, virus and host cells. Subsequently, these strains were formulated in a throat spray and human monocytes were employed to confirm the formulation process did not reduce 
the interferon regulatory pathway-inducing capacity. Administration of the throat spray in healthy volunteers revealed that the lactobacilli were capable of temporary colonization of the throat in a metabolically active form.

\section{Introduction}

Viral respiratory tract infections (RTIs) result in a significant health and economic burden, as recently highlighted by the coronavirus disease 2019 (COVID-19) pandemic [1]. Despite high prevalence of viral RTIs, few prevention or treatment options besides symptom relief are available to primary care patients. Nevertheless, RTIs can have drastic health consequences after the initial infection in the upper respiratory tract (URT), as several viruses such as influenza viruses, respiratory syncytial virus (RSV), human parainfluenza virus (HPIV) and human coronaviruses (e.g. HCoV-229E and severe acute respiratory syndrome coronavirus 2 (SARS-CoV-2)), can potentially trigger airway tissue disruption, severe inflammation $[2,3]$ and/or subsequent pneumonia $[4,5]$. Severe disease caused by viruses is often accompanied by reduced type I and III interferon (IFN) production and/or overproduction of proinflammatory mediators $[3,6,7]$. Type I and III IFNs play an important role for innate immunity at mucosal barrier surfaces, such as the respiratory epithelial barrier, where they provide first line antiviral defense mechanisms [8].

The respiratory mucosal surfaces targeted by viruses also harbor a microbiome consisting of resident microorganisms which have important multifactorial gatekeeper functions, including direct inhibition of incoming pathogens, maintaining epithelial barrier function, and immune homeostasis [9]. Importantly, the stability of the core URT microbiome can be compromised during viral RTIs, for instance as observed with influenza [10]. This can facilitate pathobiont overgrowth, as a result of virusinduced damage and immune dysfunction [11,12]. Direct supplementation of beneficial bacteria from the URT microbiome could act on different stages of viral disease, for instance via enhancement of the airway epithelial barrier, direct inhibition of pathogens or stimulation of the immune system, as we have recently reviewed [13]. Stimulation of antiviral immunity is one of the key mechanisms reported 
in animal models of respiratory viral disease upon topical administration of beneficial bacteria directly to the airways $[14,15]$.

Despite their promise, the number of clinical trials exploring URT microbiome modulation as a strategy against viral RTIs is limited. This is at least in part due to the challenge of selecting appropriate beneficial strains for the URT, and the biotechnical difficulty of formulating live microbes with a long shelf life in a liquid form [13]. Because of the convenient formulation in dry formats, combined with the fact that much more research has been performed on the gut than on the URT microbiome, oral delivery of microbiome therapeutics remains the most common administration route. The oral route focuses on probiotics that can exert systemic antiviral and anti-inflammatory effects via the gut-lung axis [16]. Nevertheless, we have recently isolated probiotic candidates Lacticaseibacillus casei AMBR2 [17] and Streptococcus salivarius strains [18] capable of respiratory pathogen inhibition from nasopharyngeal samples of healthy humans. Especially L. casei AMBR2 has shown potential as a live biotherapeutic product (LBP) due to its capacity to inhibit the growth and inflammatory characteristics of URT pathogens such as Staphylococcus aureus and promote epithelial barrier function [19-21]. Furthermore, this strain was able to temporally colonize the URT of all 20 healthy volunteers in a fitfor-purpose nasal spray formulation, without apparent side effects [19]. Also others have shown that the administration of a topical microbiome therapy containing lactic acid bacteria, such as Lactococcus lactis W139 [22], a mixture of lactobacilli and Bifidobacterium species [23], or commensal Streptococcus species [24], in the URT appears safe and could be a better targeted alternative to the indirect gut route. Indeed, lactic acid bacteria have a long history of safe use in other body sites and are therefore also promising for URT applications. Although not as high as reported for other body sites such as the gut and vagina, their prevalence and (relative) abundance in the URT is significant [25]. Moreover, lactic acid bacteria are enriched in healthy individuals compared to individuals suffering from airway diseases such as chronic rhinosinusitis [26] and can have antiviral properties [13]. Implementation of select lactic acid bacteria in high-dose URT-targeting, virus-inhibiting and immuneactive formulations is a first prerequisite before clinical studies can be designed. 
Based on documented safety, prior human use, annotated genome information and functional properties such as the capacity to inhibit bacterial and fungal pathogens and to modulate immune responses (Table 1), we selected strains of the Lactobacillaceae for dedicated immunostimulatory and antiviral screening, resulting in the selection of three strains for formulation in a throat spray. Subsequent application in human volunteers confirmed temporary retention of all three strains in the microbiome.

\section{Results}

\subsection{Screening for interferon regulatory pathway- and NF-kB-inducing Lactobacillaceae strains}

A selection of strains described in Table 1 that have previously been effectively used as probiotics in clinical trials (e.g., Lacticaseibacillus rhamnosus GG, Lactiplantibacillus plantarum WCFS1, Limosilactobacillus reuteri RC-14) and/or isolated from the URT and previously demonstrated to interact with URT cells (e.g. L. casei AMBR2, Lactiplantibacillus plantarum AMBR9) were used in this first broad screening. The strains were evaluated for their capacity to activate the interferon regulatory factor (IRF) and nuclear factor kappa B (NF-KB) immune signaling pathways in human THP-1 Dual monocytes involved in antiviral responses. Of all tested strains, L. plantarum WCFS1 most strongly activated the IRF pathway (Figure 1A), as well as NF-KB (Figure 1B). IRF induction was shown to be strain-specific with for example L. rhamnosus GG stimulating a stronger IRF and NF-KB activation compared to the other L. rhamnosus strains tested.

Based on these data and previous knowledge on their activity, L. casei AMBR2, L. plantarum WCFS1 and $L$. rhamnosus GG were selected for further analyses, as these strains have additional strain-specific properties beneficial in the URT (Table 1). Hence, a product containing a combination of strains could be more efficient due to multifactorial action, providing that the strains do not inhibit each other's activity. Indeed, combining the three strains in equal ratios also resulted in significant induction of IRF and NF-KB pathways in human monocytes, comparable to the levels observed when L. rhamnosus GG and L. plantarum WCFS1 were used separately (Figure 2C-F). Of note, the NF-KB stimulation by 
lactobacilli was significantly lower compared to the non-probiotic LPS-containing Gram-negative control Escherichia coli DH5a (Figure 1C, E). To assess whether the bacteria had to be metabolically active to induce immunostimulatory effects, ultraviolet (UV)-inactivated strains were used (Figure 1EF). Both UV-inactivated L. plantarum WCFS1 and L. rhamnosus GG, as well as the mix of the three strains, still significantly induced the IRF and NF-KB pathways, although to a lesser extent than their viable counterparts (Figure 1E-F).

\subsection{Direct antiviral activity of selected Lactobacillaceae strains against respiratory viruses}

Probiotic screening for direct antiviral activity is not routinely implemented because of the complexity of working with tripartite systems consisting of bacteria, viruses and host cells. Here, we implemented such innovative assays for common respiratory viruses. The inhibitory effects of the three selected Lactobacillaceae strains were evaluated against RSV, influenza $\mathrm{A} / \mathrm{H} 3 \mathrm{~N} 2, \mathrm{~A} / \mathrm{H} 1 \mathrm{~N} 1$ and $\mathrm{B}$ viruses, and human coronavirus strain 229 (HCoV-229E), all representing viruses that are a common cause of RTIs [27]. HCoV-229E generally causes mild symptoms, but it has several features in common with SARSCoV-2, such as homologous epitopes of the spike protein, and is suitable for high throughput screening due to biosafety level 2 [28]. To avoid bacterial metabolites interfering with the assay read-outs, the lactobacilli were UV-inactivated for the assays, retaining the capacity of bacterial cell surface molecules to sequester or block viral particles [29]. First, we established the concentration of bacteria that had to be simultaneously added with the HCoV-229E virus to inhibit the virus-induced cytopathic effect in susceptible human Huh7 cells by 50\% (antiviral EC50) (Figure 2A,B). L. casei AMBR2 and L. rhamnosus GG showed the strongest effect, with respective concentrations of $2.57 \times 10^{6}$ colony-forming units $(\mathrm{CFU}) / \mathrm{ml}$ and $5.06 \times 10^{6} \mathrm{CFU} / \mathrm{ml}$ required for $50 \%$ viral inhibition, which was lower than the required concentration of $1.26 \times 10^{7} \mathrm{CFU} / \mathrm{mL}$ for the non-probiotic E. coli DH5 $\alpha$ strain. For L. plantarum WCFS1, the required concentration for $50 \%$ viral inhibition was $1.17 \times 10^{7} \mathrm{CFU} / \mathrm{ml}$.

Subsequently, we also evaluated a set-up where the three bacterial strains or their combination in equal ratios were pre-incubated with HCoV-229E, RSV or influenza viruses, allowing trapping and/or 
inactivation of virus particles, and afterwards unbound virus particles were added to human cells

(Figure 2C). HCoV-229E (Figure 2D) and RSV (Figure 2E) pre-incubated with L. casei AMBR2, L.

rhamnosus GG, L. plantarum WCFS1 or their combination significantly lost the capacity to reduce human cell viability compared to virus pre-incubation with phosphate-buffered saline (PBS) which served as an inactive control. For example, the percentage of viable Huh7 cells infected with HCoV229E was on average $2.9 \%$ for the PBS condition, and $34 \%, 30 \%$, and $18 \%$ for $L$. casei AMBR2, $L$. rhamnosus GG, and L. plantarum WCFS1 conditions, respectively. Using the combination of the three with L. rhamnosus GG or a combination of the three lactobacilli also significantly reduced the cytopathic effects induced by the common influenza A/H1N1 virus compared to PBS (Figure 2F). A virus were less pronounced (Figure 2G). The pre-incubation of the non-probiotic control E. coli DH5 $\alpha$ with the tested viruses did not improve viability of human cells, while the cell viability in all lactobacilli conditions was significantly higher compared to E. coli $\mathrm{DH} 5 \alpha$. The potential antiviral activity of L. casei AMBR2, L. rhamnosus GG, and L. plantarum WCFS1, in addition to their other beneficial properties (Table 1) and interferon pathway induction capacity (Figure 1), led us to evaluate their combination in a throat spray formulation.

\subsection{Formulation of viable Lactobacillaceae strains in a throat spray}

L. casei AMBR2, L. rhamnosus GG, and L. plantarum WCFS1 were formulated into an oral/throattargeting spray, based on a combination of bacterial powders in an oil suspension. Although most probiotic sprays for the URT currently available consist of a bacterial suspension in saline or PBS [30], oil was chosen to increase bacterial retention in the throat and to ensure a sufficient dosage of viable probiotic CFU counts. First, the viability of each bacterial strain in freeze-dried powder form was 
time. For L. casei AMBR2 and L. plantarum WCFS1, no log reductions were observed, with $2.79 \times 10^{10}$ CFU/g powder and $3.56 \times 10^{11}$ at start for AMBR2 and WCFS1, respectively, to $2.21 \times 10^{10} \mathrm{CFU} / \mathrm{g}$ powder and $3.15 \times 10^{11} \mathrm{CFU} / \mathrm{g}$ powder after 26 weeks. For L. rhamnosus GG, the viability decreased from 1.18 $\times 10^{11} \mathrm{CFU} / \mathrm{g}$ powder to $7.15 \times 10^{10} \mathrm{CFU} / \mathrm{g}$. At room temperature $\left(25^{\circ} \mathrm{C}\right)$, L. plantarum WCFS1 seemed most stable, with 1 log reduction at 26 week $\left(5.84 \times 10^{10}\right)$, while this was $8.57 \times 10^{9}$ for L. rhamnosus GG and $2.02 \times 10^{7}$ for L. casei AMBR2.

We next evaluated different concentrations of the strains in the mixture. L. casei AMBR2 at $50 \%, L$. plantarum WCFS1 at 33.3\%, and L. rhamnosus GG at $16.7 \%$ were found the optimal ratio upon longterm storage at room temperature, which reflected the intended storage conditions. Next, the viability of the combined bacterial strains in powder form (Figure 3B) and in the throat spray formulation (Figure $3 \mathrm{C}$ ) was evaluated at $4^{\circ} \mathrm{C}, 15^{\circ} \mathrm{C}$ and $25^{\circ} \mathrm{C}$. For the mixed powders (Figure $4 \mathrm{~B}$ ), viability decreased slightly from $2.09 \times 10^{11} \mathrm{CFU} / \mathrm{g}$ at the start, to $1.11 \times 10^{11}, 4.51 \times 10^{10}$ and $8.01 \times 10^{9} \mathrm{CFU} / \mathrm{g}$ at 26 weeks of storage at $4^{\circ} \mathrm{C}, 15^{\circ} \mathrm{C}$ and $25^{\circ} \mathrm{C}$, respectively. For the spray formulation (Figure $3 \mathrm{C}$ ), viability starting with $3.78 \times 10^{9} \mathrm{CFU} / \mathrm{g}$ spray remained stable at $4^{\circ} \mathrm{C}$ and $15^{\circ} \mathrm{C}$ at 26 weeks. At $25^{\circ} \mathrm{C}$, a 2 log reduction was observed $\left(3.3 \times 10^{7} \mathrm{CFU} / \mathrm{g}\right)$ at 26 weeks.

We subsequently confirmed the retention of immunostimulatory activity in human monocytes of the strains and their combination in powder form (Figure 3D-E), and in the spray formulation in oil (Figure 3F-G). All single strains in powder form and their combination were still capable of significant IRF and NF-KB induction (Figure 4D-E) at a dose of $10^{8} \mathrm{CFU} / \mathrm{ml}$, which corresponds to the $L$. casei AMBR2 concentration per puff previously tested in healthy volunteers [19]. The immunostimulatory action of the throat spray formulation with the three strains in an oil suspension was also compared to a placebo oil formulation without lactobacilli. The throat spray formulation with $L$. casei AMBR2 at 50\%, $L$. plantarum WCFS1 at 33.3\%, and L. rhamnosus GG at $16.7 \%$ in oil significantly induced IRF and NF-KB in human monocytes (Figure 4F-G). While the placebo formulation also induced NF-KB, albeit to a lower degree compared to the spray formulation with lactobacilli, it did not significantly affect IRF. 


\subsection{Evaluation of throat colonization by lactobacilli in healthy volunteers}

181

182

183

184

185

Finally, we evaluated the retention of the lactobacilli in the formulated spray in the throat of 12 healthy volunteers via cultivation, quantitative polymerase chain reaction (qPCR) and 16S rRNA amplicon sequencing using a longitudinal placebo-controlled sampling set-up (Figure 4A). The volunteers used the verum spray at the start of the study by spraying two puffs containing approximately $9.5 \times 10^{8} \mathrm{CFU}$ of lactobacilli, or the placebo spray not containing lactobacilli, and throat swabs were collected at baseline, after $30 \mathrm{~min}$, and after 2 hours (Figure 4A).

Microbiome analysis of the throat swabs showed that the dominant bacterial genera in the throat belong to canonical throat commensals, such as Prevotella, Veillonella, and Streptococcus species. A principal coordinate analysis ( $\mathrm{PCOA}$ ) plot based on the microbiome data across all time points did not reveal a clear clustering per treatment group at any of the tested time points (Figure 4B). A clear difference in relative abundances of Lactobacillaceae amplicon sequence variants (ASVs) was observed between the placebo and verum spray groups, especially 30 minutes after the spray was used (Figure 4C). Three Lactobacillus ASVs, corresponding to the administered strains, were detected in the verum group 30 minutes after spray administration. Lactobacillus ASV 1 (L. rhamnosus) was detected in all 6 participants in the verum group, while Lactobacillus ASV 3 (L. casei) and Lactobacillus ASV 7 (L. plantarum) were detected in 5 out of 6 participants. In the placebo group, these Lactobacillus ASV were not detected, except for one participant that had low endogenous relative abundances of the Lactobacillus casei ASV after 30 minutes. After 2 hours, 5 out of 6 participants in the verum group still had detectable Lactobacillus ASVs.

To confirm and quantify the high abundances of the administered strains observed by sequencing DNA derived from samples in the verum group after bacterial administration, we aimed to estimate the CFU/ml counts based on targeted qPCR (Figure 4D). In line with the sequencing data, after 30 minutes, the estimated CFU counts for $L$. rhamnosus GG in the verum group were between $1.26 \times 10^{4}-9.24 \times 10^{5}$ $\mathrm{CFU} / \mathrm{ml}$. For L. casei AMBR2, estimated CFU/ml counts ranged from $1.72 \times 10^{5}$ to $1.8 \times 10^{7} \mathrm{CFU} / \mathrm{ml}$ and 
for L. plantarum WCFS1 from $4.63 \times 10^{4} \mathrm{CFU}-3.36 \times 10^{6} \mathrm{CFU}$. After 2 hours, the amount of detected

lactobacilli decreased. L. rhamnosus GG and L. plantarum WCFS1 were not detected anymore except

in one participant. L. casei AMBR2 on the other hand, which was administered in the highest ratio of

$\mathrm{CFU} / \mathrm{ml}$.

In addition to analyzing the DNA of the bacteria, we also cultivated throat swabs to evaluate whether

the administered lactobacilli were still viable. Cultured throat swabs from the verum group

identity was confirmed via colony PCR and sequencing of the $16 \mathrm{~S}$ rRNA gene, confirming that the administered strains are not only detected in the throat via their DNA, but also remain viable.

\section{Discussion}

Topical microbiome therapeutics can act on different stages of viral infection by multiple modes of action, which can potentially prevent a broad range of viral diseases [13]. Here, we designed and implemented a dedicated pipeline to select lactobacilli for a topical throat spray against viral RTIs (Figure 5A). We demonstrated the immunostimulatory and antiviral effects of selected lactobacilli, and also considered their safety, applicability and previously reported beneficial properties such as barrier enhancement and antipathogenic effects, important during viral RTIs. Starting from this screening, we formulated L. casei AMBR2, L. rhamnosus GG, and L. plantarum WCFS1 in a microbiome throat spray, confirmed their immunostimulatory activity in the spray formulation and the temporary colonization of the administered strains in throats of healthy volunteers.

An important property of the selected Lactobacilaceae strains was the activation of IFN regulatory pathways and NF-KB that could promote antiviral immune defenses upon topical application of the selected lactobacilli in the URT, based on the documented key role of these pathways [31]. Our results highlight that different lactobacilli isolates have strikingly variable capacities for NF-KB and IFN 
screening is required to select the optimal strain for each application. Specifically, we have identified pathway induction both in viable and, to a lesser degree, UV-inactivated form. This indicates their highest potential as live probiotics, but also as postbiotics because of retained activity in inanimate forms [32]. The strong induction of IFN pathway by L. plantarum WCFS1 is in line with earlier observations demonstrating especially strong activation by this strain of the antiviral IFIT1 (Interferon Induced Protein With Tetratricopeptide Repeats 1) gene in differentiated human monocytes [33]. Similarly, intranasal supplementation with L. rhamnosus GG was previously shown to increase survival in mouse models of influenza infection by stimulating transcription of protective type I IFN genes in the neonatal airways [15]. These immunostimulatory effects could be extrapolated to humans, as in the duodenum of healthy participants L. plantarum WCFS1 induced the NF-KB pathway linked to immune tolerance [34], while consumption of L. rhamnosus GG up-regulated IFN-induced genes and cytokine-encoding genes [35]. Importantly, we demonstrated that the combination of the selected lactobacilli retained their immunostimulatory capacity not only when cultured in laboratory conditions, but also as part of the final throat spray formulation. These results are in line with our observation that the viability of the $L$. casei AMBR2, L. rhamnosus GG, and L. plantarum WCFS1 is maintained after freeze-drying of the bacteria and resuspension in oil. The use of oil in the final spray formulation, in combination with the established adherence capacity to the respiratory epithelium of the bacterial strains themselves $[19,36,37]$ ensures their temporary retention in the throat. To the best of our knowledge, other oral sprays with probiotics have not yet used oil, but instead suspended the bacteria in saline [24]. In this study, retention of the administered lactobacilli was confirmed in vivo in healthy volunteers. We found that 30 minutes after spray administration, live L. casei AMBR2, L. rhamnosus GG, and L. plantarum WCFS1 and their DNA were detected in the throat. A contact time of 30 minutes has previously been shown to be sufficient for immune response initiation in vitro, including NF-kB induction by bacterial 
tumor necrosis factor alpha [39]. The spray was successfully tested in healthy volunteers, which opens possibilities for its preventive use. However, the dynamics of bacterial colonization in a disturbed throat environment during an active viral RTI could be different, therefore the spray should also be tested in volunteers with viral RTIs to better assess its therapeutic potential. Promisingly, our experiments here already established the delivery of a dose of live cells at their target site in healthy volunteers comparable to the amount of cells that was capable to counteract viral infection in vitro.

Our formulation ensures that the throat is the main target for bacterial interaction, in contrast to other studies on oral bacteriotherapy where the formulation is not tailored to URT applications, with most of the bacteria ending up in the gut [40]. This is important, because studies in animal models show that applying immunomodulatory lactobacilli at the site of respiratory infection or inflammation rather than in the gastrointestinal tract, promotes a more direct and efficient contact with specific cells of the URT immune system [41-44].

In addition to the important immunostimulatory effects on host cells, our in vitro results also demonstrate direct inhibitory activity of L. casei AMBR2, L. rhamnosus GG and L. plantarum WCFS1 on reduce influenza A virus A/WSN/33 (H1N1) titers in vitro [45], reduction of viral cytopathogenic effects upon direct contact with metabolically inactive lactobacilli has not yet been explored in detail, especially not for promising URT isolates such as L. casei AMBR2. Since the lactic acid bacterium Enterococcus faecium NCIMB 10415 is capable of direct adsorptive trapping of swine influenza H1N1 and H3N2 viral particles [46], we hypothesize that L. casei AMBR2, L. rhamnosus GG and L. plantarum

276 WCFS1 are also capable of sequestering HCoV-229E, RSV and influenza viral particles and directly 277 reducing their infectivity and transmission.

278 In combination with previous results, our comprehensive in vitro testing substantiated the selection of activity against different key aspects of viral respiratory diseases when combined in a URT spray (Figure 
5B). In our previous research, the potential of L. casei AMBR2 as topical probiotic for the respiratory tract is already well-established $[20,21,25]$. An important feature of this strain in the context of viral disease is its strong ability to enhance the airway epithelial barrier, as well as its adaptation to the unique URT environment, including catalase genes and adherence to the airway epithelium $[17,20,21,25]$. Probiotics such as L. casei AMBR2 and L. rhamnosus GG also inhibit URT pathobionts that can increase the morbidity and mortality of viral respiratory diseases, including Haemophilus influenzae, S. aureus and Moraxella catarrhalis $[12,19,36]$. These features, in combination with the newly reported antiviral activity in this study pave the way for a more directed topical use of the developed L. casei AMBR2, L. rhamnosus GG and L. plantarum WCFS1 throat spray against respiratory viral disease.

\section{Conclusions}

The development of rationally-selected, evidence-based sprays with probiotic lactobacilli and their employment in clinical trials is long overdue, especially in the context of viral RTI. Based on their safety, applicability in the airways, antiviral action and stimulation of antiviral immunity, L. casei AMBR2, L. rhamnosus GG and L. plantarum WCFS1 were selected as promising strains, followed by optimal formulation for topical application in the URT in a throat spray. Temporary throat colonization by the administered lactobacilli was demonstrated. The spray is a stepping stone for prevention and treatment of viral respiratory tract infections with locally applied beneficial bacteria, and will be further evaluated in primary care patients with viral respiratory tract infections.

\section{Bacterial strains used in this study and their properties are listed in Table 1. Lactobacillaceae strains} were grown statically at $37^{\circ} \mathrm{C}$ in de Man, Rogosa and Sharpe (MRS) broth (Difco, Erembodegem, Belgium). Escherichia coli DH5 $\alpha$ was cultured aerobically at $37^{\circ} \mathrm{C}$ in Luria-Bertani (LB) broth. For coincubation with viruses or human cells, bacterial pellets were obtained by centrifugation at $2000 \mathrm{~g}$ for 
10 min and washed in sterile phosphate-buffered saline (PBS). After resuspension in corresponding media (for experiments with human cells) or PBS (for antiviral activity experiments), UV inactivation of bacteria was achieved in a biosafety level 2 cabinet using four 15 min rounds of UV irradiation followed by vortexing. Bacteria were plated out to confirm inactivation.

\subsection{NF-KB and IRF induction in THP1-Dual monocytes}

THP1-Dual monocytes (Invivogen) were maintained in RPMI 1640 (ThermoFisher Scientific) medium with $10 \%$ Fetal Calf Serum (FCS), $25 \mathrm{mM} \mathrm{HEPES}$ and $2 \mathrm{mM} \mathrm{L-glutamine} \mathrm{at} 37^{\circ} \mathrm{C}, 5 \% \mathrm{CO}_{2}$. For experiments with bacteria, THP1-Dual cells were seeded in a 96-well plate at a concentration of $10^{5}$ cells/well. Bacteria were added to the cells at $10^{6} \mathrm{CFU} /$ well for live bacteria from cultures, $10^{7} \mathrm{CFU} /$ well for UVinactivated bacteria from cultures, and $10^{8} \mathrm{CFU} /$ well for powdered bacteria. Spray was added at a 1:20 dilution. The plate was incubated for 24 hours at $37^{\circ} \mathrm{C}$ and $5 \% \mathrm{CO}_{2}$. Induction of NF-kB was assessed based on SEAP reporter activity at $405 \mathrm{~nm}$ with the Synergy HTX Plate Reader (BioTek) after the addition of a para-Nitrophenylphosphate (pNPP) buffer. Induction of IRF was assessed based on luciferase reporter luminescence activity with the Synergy HTX Plate Reader (BioTek) after the addition of the QUANTI-Luc ${ }^{\text {TM }}$ (InvivoGen) buffer. Poly (I:C) with Lipofectamine 2000 (Invitrogen) at $50 \mu \mathrm{g} / \mathrm{ml}$ for IRF induction or lipopolysaccharides (LPS) from E. coli (Sigma) at $20 \mathrm{ng} / \mathrm{mL}$ for NF-KB induction were used as positive controls.

\subsection{Cell lines and viruses for antiviral assays}

Human liver carcinoma cell line Huh7 (CLS Cell Lines Service, Germany), human epidermoid carcinoma HEp-2 (ATCC CCL-23) and Madin-Darby canine kidney (MDCK) cells, a gift from Dr. M. Matrosovich (Marburg, Germany), were maintained in Dulbecco's Modified Eagle Medium (DMEM, Gibco Life Technologies) supplemented with $8 \%$ heat-inactivated fetal bovine serum (HyClone, GE Healthcare Life Sciences), and maintained at $37^{\circ} \mathrm{C}$ under $5 \% \mathrm{CO}_{2}$.

Human coronavirus (HCoV-229E) and respiratory syncytial virus (RSV Long) were purchased from ATCC (VR-740 and VR-26, respectively). The human influenza virus strains used are as follows: A/Ned/378/05 
(A/H1N1 subtype) and B/Ned/537/05 (B/Yamagata lineage), clinical isolates generously donated by

Prof. R. Fouchier (Rotterdam, The Netherlands), and A/HK/7/87 (A/H3N2 subtype) was obtained from Prof. J. Neyts (KU Leuven, Belgium). influenza viruses in human cells

Bacterial strains were prepared as described above with UV-inactivation. The antiviral evaluation of UV-inactivated bacteria against HCoV-229E was performed by seeding Huh7 cells into 384-well plates.

After $24 \mathrm{~h}$ at $37^{\circ} \mathrm{C}, 5$ fold serial dilutions of the bacteria (or PBS as a negative control) were added to per well. At 3 days post-infection, the virus-induced cytopathogenic effect was measured colorimetrically by the formazan-based 3-(4,5-dimethylthiazol-2-yl)-5-(3-carboxymethoxyphenyl)-2(4-sulfophenyl)-2H-tetrazolium (MTS) cell viability assay (CellTiter 96 AQueous One Solution Cell Proliferation Assay from Promega, Madison, WI), and the antiviral activity was expressed as the $50 \%$ effective concentration $\left(\mathrm{EC}_{50}\right)$. In parallel, the $50 \%$ cytotoxic concentration $\left(\mathrm{CC}_{50}\right)$ was derived from mock-infected cells.

The evaluation of viral inhibition by UV-inactivated bacteria after pre-incubation with influenza viruses (A/H1N1 A/Ned/378/05, $\mathrm{A} / \mathrm{H} 3 \mathrm{~N} 2 \mathrm{~A} / \mathrm{HK} / 7 / 87$ and $\mathrm{B} / \mathrm{Ned} / 537 / 05)$, respiratory syncytial virus and human coronavirus (HCoV-229E) was performed by seeding MDCK, HEp-2 or Huh7 cells into 384-well dishes, respectively, and the plates were incubated for $24 \mathrm{~h}$ at $35^{\circ} \mathrm{C}$ (MDCK) or $37^{\circ} \mathrm{C}$ (HEp-2 and Huh7). One hour prior to infection, aliquots of UV-inactivated bacteria in PBS (or PBS alone as a negative control) were centrifuged and the pellets were resuspended in an equal volume of infection medium containing the viruses diluted to yield $30 \mathrm{CCID}_{50}$ per well at infection. The mixtures were incubated at $37^{\circ} \mathrm{C}, 5 \% \mathrm{CO}_{2}$ for $1 \mathrm{~h}$, and subsequently centrifuged ( $3000 \mathrm{~g}$ for 15 minutes at room temperature). The

354 virus containing supernatants were used for infection of the respective virus host cells. At 3 days 
measured colorimetrically by the formazan-based MTS assay, and the antiviral activity was expressed as the $\%$ viability relative to the uninfected control. In parallel, the \% viability was measured in mockinfected MDCK, HEp-2 or Huh7 cells to assess possible cytotoxic effects. rhamnosus GG, in a ratio of $50 \%, 33.3 \%$ and $16.7 \%$, respectively. Viability of the powders from the individual strains was assessed at $4^{\circ} \mathrm{C}$ and $25^{\circ} \mathrm{C}$ every 4 weeks over a time period of 6 months via resuspension of the powders in PBS and plating out serial dilutions on MRS agar. The amount of CFU/g powder was evaluated compared to the start concentration. For the mixture of the powders or the final spray formulation, viability was assessed at $4^{\circ} \mathrm{C}, 15^{\circ} \mathrm{C}$ and $25^{\circ} \mathrm{C}$ over a period of 6 months. Every 4 weeks, powders (after suspension in PBS) or spray were plated out in serial dilutions on MRS agar to measure the amount of CFU/g powder or spray.

\subsection{Evaluation of lactobacilli retention in the throat of healthy participants}

To evaluate whether the bacteria in the spray are able to temporary colonize the throat, 12 healthy male and female adult participants were asked to use the spray and collect swabs of the throat at the start, after 30 minutes, and after 2 hours of spray administration. The study was conducted according NCT04793997). Informed consent was obtained from all participants involved in this study prior to inclusion. Samples were registered and stored at the Biobank Antwerpen, Antwerp, Belgium; ID: BE 71030031000.

At each time point, 2 throat swabs were collected with eNAT ${ }^{\mathrm{TM}}$ swabs for microbial DNA extraction using the PowerFecal DNA isolation kit (Qiagen), and in PBS for lactobacilli cultivation on MRS agar. 
2017,2019). For qPCR analysis, species-specific primers for L. casei AMBR2, L. plantarum WCFS1 and L.

rhamnosus GG were designed (Table 2). Initially, a standard curve for each species was made to estimate the Ct $\sim$ CFU ratio. The expression of the genes was quantified by RT-qPCR on a StepOne Plus sample was amplified with PowerSYBR ${ }^{\circledR}$ Green PCR Master Mix (Applied Biosystems) in a total volume of $20 \mu \mathrm{L}$ with $0.15 \mu \mathrm{M}$ of each primer, $40 \mathrm{ng}$ of cDNA and nuclease-free water.

Throat swabs were collected by swabbing along the back of the throat and both tonsils and cultivated 3') primers.

\subsection{Statistical data analysis}

Data from in vitro assays was analysed in GraphPad Prism version 9.2.0. Normality testing was performed on data from in vitro assays with bacteria using the Kolmogorov-Smirnov test followed by One-way ANOVA with Dunnett's multiple comparisons test, or the Kruskal-Wallis test with Dunn's multiple comparisons test. Differences were considered significant at $p<0.05$.

The datasets generated and analysed during the current study are available in the European Nucleotide

Archive (ENA) under accession number PRJEB49183 after publication of this manuscript.

\subsection{Funding}

402 IDB and IS were supported by grants from Research Foundation - Flanders (Fonds Wetenschappelijk 403 Onderzoek (FWO) postdoctoral grants $12 \mathrm{~S} 4222 \mathrm{~N}$ and $1277222 \mathrm{~N}$ ). TH, AS, IG, and IC were supported 
Ondernemen grant HBC.2020.2923; www.vlaio.be/en). SL was supported by the European Research Council grant Lacto-Be 26850.

\subsection{Conflict of Interest}

A patent application BE2021/5643 (priority patent application filed on 12/08/2021) titled "Sprayable formulation comprising viable and/or stable bacteria" has been filed based on the results of this work. TH, AS, IG and IC are employees of YUN NV. SL is chairperson of the scientific advisory board of YUN NV. PAB is a consultant for multiple companies in the food and health industry, but they were not involved in this manuscript. Other authors declare no conflict of interest.

\subsection{Author Contributions}

Conceptualization, SL, IDB, IS, IC, TH, PAB, PD, SC, VV, MvdB; methodology, IDB, IS, SL, LP, IC, TH, AS, IG, LD, EC; validation, IDB, IS, EC, LD, TH, AS, IG; formal analysis, IDB, IS, EC, LP, AS; investigation, IDB, IS, EC, LD, LP, TH, AS, PAB, SL, IG, LP; resources, SL, DS, IC, PD; data curation, IDB, IS, EC, TH, IC; writingoriginal draft preparation, IDB, IS, SL; writing-review and editing, all authors; visualization, IDB, IS, EC, AS; project administration, IDB, IS, SL, TH, IC; funding acquisition, SL, DS, IC. All authors have read and agreed to the published version of the manuscript.

\subsection{Acknowledgments}

The authors want to thank the entire research group of the Lab of Applied Microbiology and Biotechnology of the University of Antwerp. We would also like to thank Kate Van Loock and Lorenzo Carreon for the help with the formulation development and the Biobank Antwerpen for the storage and registration of samples of human origin.

\section{References}

1. Dong E, Du H, Gardner L. An interactive web-based dashboard to track COVID-19 in real time. Lancet Infect Dis [Internet]. 2020;20:533-4. Available from: http://www.sciencedirect.com/science/article/pii/S1473309920301201

2. Blanco-Melo D, Nilsson-Payant BE, Liu WC, Uhl S, Hoagland D, Møller R, et al. Imbalanced Host 

during influenza: viral determinants and hemostasis are caught as culprits. Cell Mol Life Sci [Internet]. 2014;71:885-98. Available from: https://doi.org/10.1007/s00018-013-1479-x

4. Zhou F, Yu T, Du R, Fan G, Liu Y, Liu Z, et al. Clinical course and risk factors for mortality of adult inpatients with COVID-19 in Wuhan, China: a retrospective cohort study. Lancet [Internet]. Elsevier; 2020;395:1054-62. Available from: https://doi.org/10.1016/S0140-6736(20)30566-3

5. Ruuskanen O, Lahti E, Jennings LC, Murdoch DR. Viral pneumonia. Lancet (London, England) [Internet]. 2011/03/22. Elsevier Ltd.; 2011;377:1264-75. Available from: https://pubmed.ncbi.nlm.nih.gov/21435708

6. Blanco-Melo D, Nilsson-Payant BE, Liu W-C, Uhl S, Hoagland D, Møller R, et al. Imbalanced Host Response to SARS-CoV-2 Drives Development of COVID-19. Cell [Internet]. 2020;181:1036-1045.e9. Available from: http://www.sciencedirect.com/science/article/pii/S009286742030489X

7. Jérôme $H$, Nader $Y$, Laura B, Aurélien C, Jeremy B, Nikaïa S, et al. Impaired type I interferon activity and inflammatory responses in severe COVID-19 patients. Science (80- ) [Internet]. American Association for the Advancement of Science; 2020;369:718-24. Available from: https://doi.org/10.1126/science.abc6027

8. Stanifer ML, Guo C, Doldan P, Boulant S. Importance of Type I and III Interferons at Respiratory and Intestinal Barrier Surfaces [Internet]. Front. Immunol. . 2020. p. 3240. Available from: https://www.frontiersin.org/article/10.3389/fimmu.2020.608645

9. Man WH, de Steenhuijsen Piters WAA, Bogaert D. The microbiota of the respiratory tract: gatekeeper to respiratory health. Nat Rev Microbiol [Internet]. 2017;15:259-70. Available from: https://doi.org/10.1038/nrmicro.2017.14

10. Kaul D, Rathnasinghe R, Ferres M, Tan GS, Barrera A, Pickett BE, et al. Microbiome disturbance and resilience dynamics of the upper respiratory tract during influenza A virus infection. Nat Commun [Internet]. 2020;11:2537. Available from: https://doi.org/10.1038/s41467-020-16429-9

11. DeMuri GP, Gern JE, Eickhoff JC, Lynch S V, Wald ER. Dynamics of Bacterial Colonization With Streptococcus pneumoniae, Haemophilus influenzae, and Moraxella catarrhalis During Symptomatic and Asymptomatic Viral Upper Respiratory Tract Infection. Clin Infect Dis [Internet]. 2017;66:1045-53. Available from: https://doi.org/10.1093/cid/cix941

12. Morris DE, Cleary DW, Clarke SC. Secondary Bacterial Infections Associated with Influenza 
461

462

463

464

465

466

467

468

469

470

471

472

473

474

475

476

477

478

479

480

481

482

483

484

485

486

487

488

489

490

491

Pandemics. Front Microbiol [Internet]. Frontiers Media S.A.; 2017;8:1041. Available from: https://pubmed.ncbi.nlm.nih.gov/28690590

13. Spacova I, De Boeck I, Bron PA, Delputte P, Lebeer S. Topical Microbial Therapeutics against Respiratory Viral Infections. Trends Mol Med. England; 2021;27:538-53.

14. Harata G, He F, Hiruta N, Kawase M, Kubota A, Hiramatsu M, et al. Intranasal administration of Lactobacillus rhamnosus GG protects mice from H1N1 influenza virus infection by regulating respiratory immune responses. Lett Appl Microbiol [Internet]. John Wiley \& Sons, Ltd; 2010;50:597602. Available from: https://doi.org/10.1111/j.1472-765X.2010.02844.x

15. Kumova OK, Fike AJ, Thayer JL, Nguyen LT, Mell JC, Pascasio J, et al. Lung transcriptional unresponsiveness and loss of early influenza virus control in infected neonates is prevented by intranasal Lactobacillus rhamnosus GG [Internet]. PLoS Pathog. Microbiology and Immunology, Drexel University College of Medicine, Philadelphia, PA, United States of America.; 2019. p. e1008072. Available from: http://europepmc.org/abstract/MED/31603951

16. Dang AT, Marsland BJ. Microbes, metabolites, and the gut-lung axis. Mucosal Immunol [Internet]. 2019;12:843-50. Available from: https://doi.org/10.1038/s41385-019-0160-6

17. Wuyts S, Wittouck S, De Boeck I, Allonsius CN, Pasolli E, Segata N, et al. Large-Scale Phylogenomics of the Lactobacillus casei Group Highlights Taxonomic Inconsistencies and Reveals Novel CladeAssociated Features. mSystems. American Society for Microbiology Journals; 2017;2:e00061-17.

18. Jörissen J, van den Broek MFL, De Boeck I, Van Beeck W, Wittouck S, Boudewyns A, et al. CaseControl Microbiome Study of Chronic Otitis Media with Effusion in Children Points at Streptococcus salivarius as a Pathobiont-Inhibiting Species. mSystems. 2021;6.

19. De Boeck I, van den Broek MFL, Allonsius CN, Spacova I, Wittouck S, Martens K, et al. Lactobacilli Have a Niche in the Human Nose. Cell Rep [Internet]. 2020;31:107674. Available from: http://www.sciencedirect.com/science/article/pii/S2211124720306276

20. De Rudder C, Garcia-Tímermans C, De Boeck I, Lebeer S, Van de Wiele T, Calatayud Arroyo M. Lacticaseibacillus casei AMBR2 modulates the epithelial barrier function and immune response in a donor-derived nasal microbiota manner. Sci Rep [Internet]. 2020;10:16939. Available from: https://doi.org/10.1038/s41598-020-73857-9

21. Martens K, De Boeck I, Jokicevic K, Kiekens F, Farré R, Vanderveken OM, et al. Lacticaseibacillus casei AMBR2 Restores Airway Epithelial Integrity in Chronic Rhinosinusitis With Nasal Polyps. Allergy Asthma Immunol Res. 2021;13:560-75. 
22. Endam LM, Alromaih S, Gonzalez E, Madrenas J, Cousineau B, Renteria AE, et al. Intranasal Application of Lactococcus lactis W136 Is Safe in Chronic Rhinosinusitis Patients With Previous Sinus Surgery. Front Cell Infect Microbiol. 2020;10:440.

23. Mårtensson $A$, Abolhalaj $M$, Lindstedt $M$, Mårtensson $A$, Olofsson $T C$, Vásquez $A$, et al. Clinical efficacy of a topical lactic acid bacterial microbiome in chronic rhinosinusitis: A randomized controlled trial. Laryngoscope Investig Otolaryngol. Wiley-Blackwell; 2017;2:410-6.

24. Andaloro C, Santagati M, Stefani S, La Mantia I. Bacteriotherapy with Streptococcus salivarius $24 S M B$ and Streptococcus oralis $89 a$ oral spray for children with recurrent streptococcal pharyngotonsillitis: a randomized placebo-controlled clinical study. Eur Arch Oto-Rhino-Laryngology. 2019;276:879-87.

25. De Boeck I, Spacova I, Vanderveken OM, Lebeer S. Lactic acid bacteria as probiotics for the nose? Microb Biotechnol. 2021;14:859-69.

26. De Boeck I, Wittouck S, Martens K, Claes J, Jorissen M, Steelant B, et al. Anterior Nares Diversity and Pathobionts Represent Sinus Microbiome in Chronic Rhinosinusitis. Young VB, editor. mSphere [Internet]. 2019;4:e00532-19. Available from: http://msphere.asm.org/content/4/6/e0053219.abstract

27. leven M, Coenen S, Loens K, Lammens C, Coenjaerts F, Vanderstraeten A, et al. Aetiology of lower respiratory tract infection in adults in primary care: a prospective study in 11 European countries. Clin Microbiol Infect. 2018;24:1158-63.

28. Mateus J, Grifoni A, Tarke A, Sidney J, Ramirez SI, Dan JM, et al. Selective and cross-reactive SARSCoV-2 T cell epitopes in unexposed humans. Science. 2020;370:89-94.

29. Malik S, Petrova MI, Imholz NCE, Verhoeven TLA, Noppen S, Van Damme EJM, et al. High mannosespecific lectin MsI mediates key interactions of the vaginal Lactobacillus plantarum isolate CMPG5300. Sci Rep [Internet]. Nature Publishing Group; 2016;6:37339. Available from: https://pubmed.ncbi.nlm.nih.gov/27853317

30. Andaloro C, Santagati M, Stefani S, La Mantia I. Bacteriotherapy with Streptococcus salivarius $24 S M B$ and Streptococcus oralis $89 a$ oral spray for children with recurrent streptococcal pharyngotonsillitis: a randomized placebo-controlled clinical study. Eur Arch Oto-Rhino-Laryngology [Internet]. 2019;276:879-87. Available from: https://doi.org/10.1007/s00405-019-05346-3

31. Hiscott J. Convergence of the NF-KB and IRF pathways in the regulation of the innate antiviral response. Cytokine Growth Factor Rev [Internet]. 2007;18:483-90. Available from: 
32. Salminen S, Collado MC, Endo A, Hill C, Lebeer S, Quigley EMM, et al. The International Scientific Association of Probiotics and Prebiotics (ISAPP) consensus statement on the definition and scope of postbiotics. Nat Rev Gastroenterol Hepatol 2021 189. Nature Publishing Group; 2021;18:649-67. activate type-I interferon production via the intracellular cytosolic sensors STING and MAVS. Gut Microbes [Internet]. 2020/01/15. Taylor \& Francis; 2020;11:771-88. Available from: https://pubmed.ncbi.nlm.nih.gov/31941397 NF-kappaB pathways induction by Lactobacillus plantarum in the duodenum of healthy humans correlating with immune tolerance. Proc Natl Acad Sci U S A. 2009;106:2371-6. mucosal in vivo transcriptome responses to three lactobacilli indicate how probiotics may modulate human cellular pathways. Proc Natl Acad Sci U S A [Internet]. 2010/09/07. National Academy of Sciences; 2011;108 Suppl:4562-9. Available from: https://pubmed.ncbi.nlm.nih.gov/20823239 against the respiratory tract pathogen Moraxella catarrhalis. Benef Microbes. Netherlands; 2018;9:429-39.

37. Pretzer G, Snel J, Molenaar D, Wiersma A, Bron PA, Lambert J, et al. Biodiversity-based identification and functional characterization of the mannose-specific adhesin of Lactobacillus plantarum. J Bacteriol. 2005;

38. Hobbs S, Reynoso M, Geddis A V, Mitrophanov AY, Matheny Jr RW. LPS-stimulated NF-KB p65 dynamic response marks the initiation of TNF expression and transition to IL-10 expression in RAW 264.7 macrophages. Physiol Rep [Internet]. John Wiley and Sons Inc.; 2018;6:e13914-e13914. Available from: https://pubmed.ncbi.nlm.nih.gov/30426723

39. Confalone E, D’Alessio G, Furia A. IL-6 Induction by TNF $\alpha$ and IL-1 $\beta$ in an Osteoblast-Like Cell Line. 549 Int J Biomed Sci [Internet]. Master Publishing Group; 2010;6:135-40. Available from: https://pubmed.ncbi.nlm.nih.gov/23675187 
Intranasal Administration of Lactobacillus paracasei NCC2461 Modulates Allergic Airway Inflammation in Mice. Cong Y, editor. Int J Inflam [Internet]. Hindawi Publishing Corporation; 2012;2012:686739. Available from: https://doi.org/10.1155/2012/686739

42. Spacova I, Petrova MI, Fremau A, Pollaris L, Vanoirbeek J, Ceuppens JL, et al. Intranasal administration of probiotic Lactobacillus rhamnosus GG prevents birch pollen-induced allergic asthma in a murine model. Allergy [Internet]. John Wiley \& Sons, Ltd; 2019;74:100-10. Available from: https://doi.org/10.1111/all.13502

43. Yang W-T, Yang G-L, Shi S-H, Liu Y-Y, Huang H-B, Jiang Y-L, et al. Protection of chickens against H9N2 avian influenza virus challenge with recombinant Lactobacillus plantarum expressing conserved antigens. Appl Microbiol Biotechnol [Internet]. 2017;101:4593-603. Available from: https://doi.org/10.1007/s00253-017-8230-8

44. Youn H-N, Lee D-H, Lee Y-N, Park J-K, Yuk S-S, Yang S-Y, et al. Intranasal administration of live Lactobacillus species facilitates protection against influenza virus infection in mice. Antiviral Res [Internet]. 2012;93:138-43.

Available

from: http://www.sciencedirect.com/science/article/pii/S0166354211005055

45. Lange-Starke A, Petereit A, Truyen U, Braun PG, Fehlhaber K, Albert T. Antiviral Potential of Selected Starter Cultures, Bacteriocins and D,L-Lactic Acid. Food Environ Virol. 2014;6:42-7.

46. Wang Z, Chai W, Burwinkel M, Twardziok S, Wrede P, Palissa C, et al. Inhibitory Influence of Enterococcus faecium on the Propagation of Swine Influenza A Virus In Vitro. PLoS One [Internet]. Public Library of Science; 2013;8:e53043.

Available from: https://doi.org/10.1371/journal.pone.0053043

47. van den Nieuwboer M, van Hemert S, Claassen E, de Vos WM. Lactobacillus plantarum WCFS1 and its host interaction: a dozen years after the genome. Microb Biotechnol. 2016;9:452-65.

48. Anukam KC, Macklaim JM, Gloor GB, Reid G, Boekhorst J, Renckens B, et al. Genome sequence of Lactobacillus pentosus KCA1: vaginal isolate from a healthy premenopausal woman. PLoS One [Internet]. 2013/03/19. Public Library of Science; 2013;8:e59239-e59239. Available from: https://pubmed.ncbi.nlm.nih.gov/23527145

49. Onwuliri V, Agbakoba NR, Anukam KC. Topical cream containing live lactobacilli decreases malodorproducing bacteria and downregulates genes encoding PLP-dependent enzymes on the axillary skin microbiome of healthy adult Nigerians. J Cosmet Dermatol. England; 2021;20:2989-98.

50. Reid G, Charbonneau D, Erb J, Kochanowski B, Beuerman D, Poehner R, et al. Oral use of 
Lactobacillus rhamnosus GR-1 and L. fermentum RC-14 significantly alters vaginal flora: randomized, placebo-controlled trial in 64 healthy women. FEMS Immunol Med Microbiol. England; 2003;35:1314.

51. Merenstein D, Murphy M, Fokar A, Hernandez RK, Park H, Nsouli H, et al. Use of a fermented dairy probiotic drink containing Lactobacillus casei (DN-114 001) to decrease the rate of illness in kids: the DRINK study. A patient-oriented, double-blind, cluster-randomized, placebo-controlled, clinical trial. Eur J Clin Nutr. 2010;64:669-77.

52. Guillemard E, Tondu F, Lacoin F, Schrezenmeir J. Consumption of a fermented dairy product containing the probiotic Lactobacillus casei DN-114001 reduces the duration of respiratory infections in the elderly in a randomised controlled trial. Br J Nutr. England; 2010;103:58-68.

53. Hori T, Kiyoshima J, Shida K, Yasui H. Augmentation of cellular immunity and reduction of influenza virus titer in aged mice fed Lactobacillus casei strain Shirota. Clin Diagn Lab Immunol [Internet]. American Society for Microbiology; 2002;9:105-8. Available from: https://pubmed.ncbi.nlm.nih.gov/11777838

54. Muyyarikkandy MS, Amalaradjou MA. Lactobacillus bulgaricus, Lactobacillus rhamnosus and Lactobacillus paracasei Attenuate Salmonella Enteritidis, Salmonella Heidelberg and Salmonella Typhimurium Colonization and Virulence Gene Expression In Vitro. Int J Mol Sci. 2017;18.

55. Pankiewicz U, Góral M, Kozłowicz K, Góral D. Application of pulsed electric field in production of ice cream enriched with probiotic bacteria (L. rhamnosus B 442) containing intracellular calcium ions. J Food Eng [Internet]. 2020;275:109876. Available from: https://www.sciencedirect.com/science/article/pii/S0260877419305199

56. Saxelin $M$, Lassig A, Karjalainen $H$, Tynkkynen $S$, Surakka A, Vapaatalo $H$, et al. Persistence of probiotic strains in the gastrointestinal tract when administered as capsules, yoghurt, or cheese. Int J Food Microbiol. Netherlands; 2010;144:293-300.

57. Gaudana SB, Dhanani AS, Bagchi T. Probiotic attributes of Lactobacillus strains isolated from food and of human origin. Br J Nutr. England; 2010;103:1620-8.

58. Pot B, Hertel C, Ludwig W, Descheemaeker P, Kersters K, Schleifer KH. Identification and classification of Lactobacillus acidophilus, L. gasseri and L. johnsonii strains by SDS-PAGE and rRNAtargeted oligonucleotide probe hybridization. J Gen Microbiol. England; 1993;139:513-7.

59. Laboratories BR. BRL pUC host: E. coli DH5a competent cells. Focus (Madison). 1986;8:9. 
Table 1. Bacterial strains used in this study and their properties.

\begin{tabular}{|c|c|c|c|}
\hline Strain & Origin & Properties & References \\
\hline $\begin{array}{l}\text { Lacticaseibacillus } \\
\text { casei AMBR2 }\end{array}$ & $\begin{array}{l}\text { Human URT } \\
\text { isolate }\end{array}$ & $\begin{array}{l}\text { URT probiotic candidate with immunomodulatory } \\
\text { and anti-pathogenic action against URT } \\
\text { pathobionts and the associated inflammation. } \\
\text { Has epithelial barrier-promoting properties. } \\
\text { Demonstrated safety and colonization upon } \\
\text { administration in a nasal spray in healthy } \\
\text { volunteers. }\end{array}$ & {$[19,21]$} \\
\hline $\begin{array}{l}\text { Lacticaseibacillus } \\
\text { rhamnosus GG } \\
\text { (ATCC 53103) }\end{array}$ & $\begin{array}{l}\text { Human } \\
\text { gastrointestinal } \\
\text { tract isolate }\end{array}$ & $\begin{array}{l}\text { Model oral probiotic strain with anti-pathogenic, } \\
\text { barrier-enhancing and immunomodulating } \\
\text { properties. Topical URT application in mouse } \\
\text { models of influenza led to immune stimulation of } \\
\text { antiviral interferon and cytokine pathways. }\end{array}$ & {$[14,15,36]$} \\
\hline $\begin{array}{l}\text { Lactiplantibacillus } \\
\text { plantarum WCFS1 }\end{array}$ & $\begin{array}{l}\text { Human saliva } \\
\text { isolate }\end{array}$ & $\begin{array}{l}\text { Model oral probiotic strain with anti-pathogenic, } \\
\text { barrier-enhancing and immunomodulating } \\
\text { properties. In vivo administration to the URT has } \\
\text { not been reported, however NF-KB pathway } \\
\text { induction linked to immune tolerance in the } \\
\text { duodenum of healthy humans was } \\
\text { demonstrated. }\end{array}$ & {$[34,47]$} \\
\hline $\begin{array}{l}\text { Lactiplantibacillus } \\
\text { pentosus KCA1 }\end{array}$ & $\begin{array}{l}\text { Human vaginal } \\
\text { isolate }\end{array}$ & $\begin{array}{l}\text { Well-characterized probiotic strain linked with } \\
\text { microbiome modulation upon oral and topical } \\
\text { skin application }\end{array}$ & {$[48,49]$} \\
\hline $\begin{array}{l}\text { Limosilactobacillus } \\
\text { reuteri } \mathrm{RC} 14\end{array}$ & $\begin{array}{l}\text { Human vaginal } \\
\text { isolate }\end{array}$ & $\begin{array}{l}\text { Vaginal microbiome modulation upon topical } \\
\text { application together with L. rhamnosus GR-1 }\end{array}$ & {$[50]$} \\
\hline $\begin{array}{l}\text { Lacticaseibacillus } \\
\text { paracasei } \\
\text { Immunitas } \\
\text { (DN-114001) }\end{array}$ & Origin unclear & $\begin{array}{l}\text { Commercial probiotic strain from Actimel } \\
\text { Immunitas or Defensis, leads to a decrease in } \\
\text { symptoms and duration of respiratory tract } \\
\text { infections in clinical trials with children and the } \\
\text { elderly }\end{array}$ & $\begin{array}{l}{[51,52]} \\
\text { Taxonomy cfr. } \\
{[17]}\end{array}$ \\
\hline $\begin{array}{l}\text { Lacticaseibacillus } \\
\text { paracasei Shirota } \\
\text { (previously }\end{array}$ & $\begin{array}{l}\text { Human } \\
\text { gastrointestinal } \\
\text { tract isolate }\end{array}$ & $\begin{array}{l}\text { Commercial probiotic strain from the } \text { Yakult }^{\circledast} \\
\text { product (Yakult Ltd.), ameliorates influenza virus } \\
\text { infection in a mouse model }\end{array}$ & $\begin{array}{l}\text { [53] } \\
\text { Taxonomy cfr. } \\
{[17]}\end{array}$ \\
\hline $\begin{array}{l}\text { Lacticaseibacillus } \\
\text { rhamnosus B442 }\end{array}$ & $\begin{array}{l}\text { USDA } \\
\text { Agriculture } \\
\text { Research } \\
\text { Service (NRRL) } \\
\text { Culture } \\
\text { Collection }\end{array}$ & $\begin{array}{l}\text { Proposed probiotic strain for use in ice cream } \\
\text { active against enteric pathogens }\end{array}$ & {$[54,55]$} \\
\hline $\begin{array}{l}\text { Lacticaseibacillus } \\
\text { rhamnosus LC705 }\end{array}$ & Dairy strain & $\begin{array}{l}\text { Commercial probiotic used by companies such as } \\
\text { Valio, administered as part of probiotic mixtures } \\
\text { in yogurt }\end{array}$ & [56] \\
\hline $\begin{array}{l}\text { Lactiplantibacillus } \\
\text { plantarum } \\
\text { ATCC } 8014\end{array}$ & $\begin{array}{l}\text { Deposited to } \\
\text { ATCC by E. } \\
\text { McCoy as "17- } \\
5 \text { (Lactobacillus } \\
\text { arabinosus)" }\end{array}$ & $\begin{array}{l}\text { Model strain of L. plantarum with anti-pathogenic } \\
\text { properties, }\end{array}$ & [57] \\
\hline $\begin{array}{l}\text { Lactobacillus } \\
\text { acidophilus LMG } \\
\mathbf{8 1 5 1}\end{array}$ & $\begin{array}{l}\text { Isolate from } \\
\text { commercial } \\
\text { acidophilus } \\
\text { milk }\end{array}$ & $\begin{array}{l}\text { Commercial probiotic strain, deposited by the } \\
\text { Culture Collection University of Göteborg (CCUG), } \\
\text { Department of Clinical Bacteriology, Institute of } \\
\text { Clinical Bacteriology, Immunology, and Virology } \\
\text { under number CCUG } 12853\end{array}$ & [58] \\
\hline
\end{tabular}




\begin{tabular}{|l|l|l|l|}
\hline $\begin{array}{l}\text { Latilactobacillus } \\
\text { sakei AMBR8 }\end{array}$ & $\begin{array}{l}\text { Healthy human } \\
\text { URT isolate }\end{array}$ & $\begin{array}{l}\text { Strain isolated from and potentially adapted to } \\
\text { the human URT (e.g., adherence to airway } \\
\text { epithelial cells) with immunomodulatory and } \\
\text { anti-pathogenic action against URT pathobionts }\end{array}$ & {$[$ [19] } \\
\hline $\begin{array}{l}\text { Lactiplantibacillus } \\
\text { plantarum AMBR9 }\end{array}$ & $\begin{array}{l}\text { Healthy human } \\
\text { URT isolate }\end{array}$ & $\begin{array}{l}\text { Strain isolated from and potentially adapted to } \\
\text { the human URT with anti-pathogenic action } \\
\text { against URT pathobionts }\end{array}$ & {$[19]$} \\
\hline $\begin{array}{l}\text { Escherichia coli } \\
\text { DH5 } \boldsymbol{\alpha}\end{array}$ & $\begin{array}{l}\text { Laboratory } \\
\text { strain }\end{array}$ & $\begin{array}{l}\text { Laboratory strain of } \text { E. coli carrying mutations } \\
\text { that facilitate efficient transformation }\end{array}$ & {$[$ [59] } \\
\hline
\end{tabular}

Table 2. qPCR primers used in this study.

\begin{tabular}{|l|l|l|}
\hline Gene & Target species & Study \\
\hline Srr2 (2759F) & L. casei AMBR2 & {$[19]$} \\
5'-CCCGGGCCGTTACGTTGCAGGCAAAA-3' & & \\
\hline $\begin{array}{l}\text { Srr2 (2841R) } \\
\text { 5'-ACTAGTTAATTGGTCAGTCGGTGCCC-3' }\end{array}$ & L. casei AMBR2 & {$[19]$} \\
\hline $\begin{array}{l}\text { LGG_443_F } \\
\text { '5'-CGTAGCTCTTTGCGTCATCT-3' }\end{array}$ & L. rhamnosus GG & This study \\
\hline $\begin{array}{l}\text { LGG_443_R } \\
\text { 5'-CGCATTGTATGCAGCCTTATTC-3' }\end{array}$ & L. rhamnosus GG & This study \\
\hline $\begin{array}{l}\text { WCSF1_413_F } \\
\text { 5'-GCCACAACACTTCAGCAATAC-3' }\end{array}$ & L. plantarum WCFS1 & This study \\
\hline $\begin{array}{l}\text { WCSF1_413_R } \\
\text { 5'-GTGCCATACACCCTGGTAAG-3' }\end{array}$ & L. plantarum WCFS1 & This study \\
\hline
\end{tabular}


bioRxiv preprint doi: https://doi.org/10.1101/2022.01 25.477549; this version posted January 25, 2022. The copyright holder for this preprint (which was not certified by peer review) is the author/funder, who has granted bioRxiv a license to display the preprint in perpetuity. It is made available under aCC-BY-NC-ND 4.0 International license.

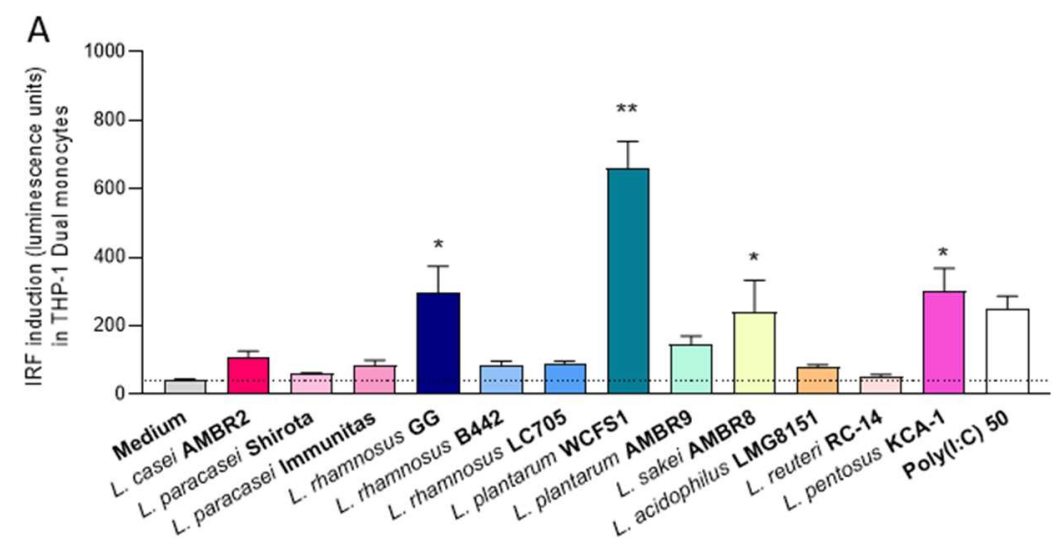

B

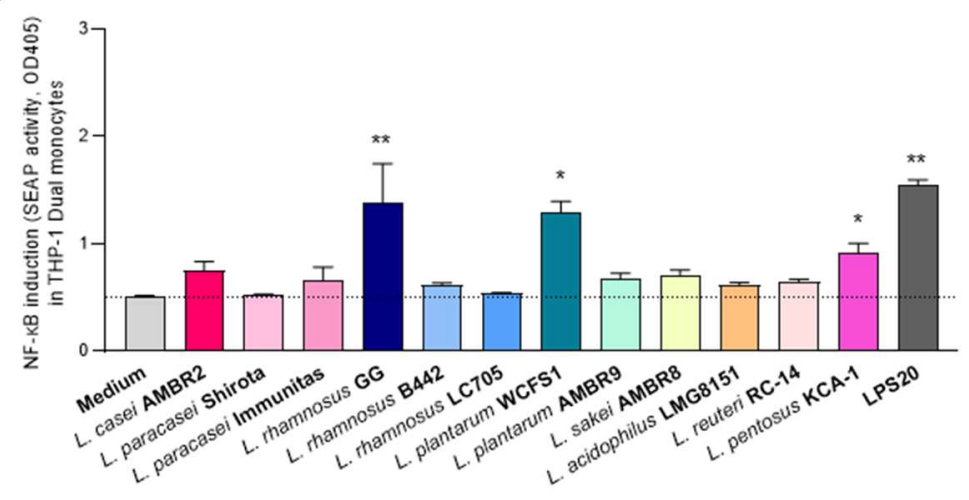

c
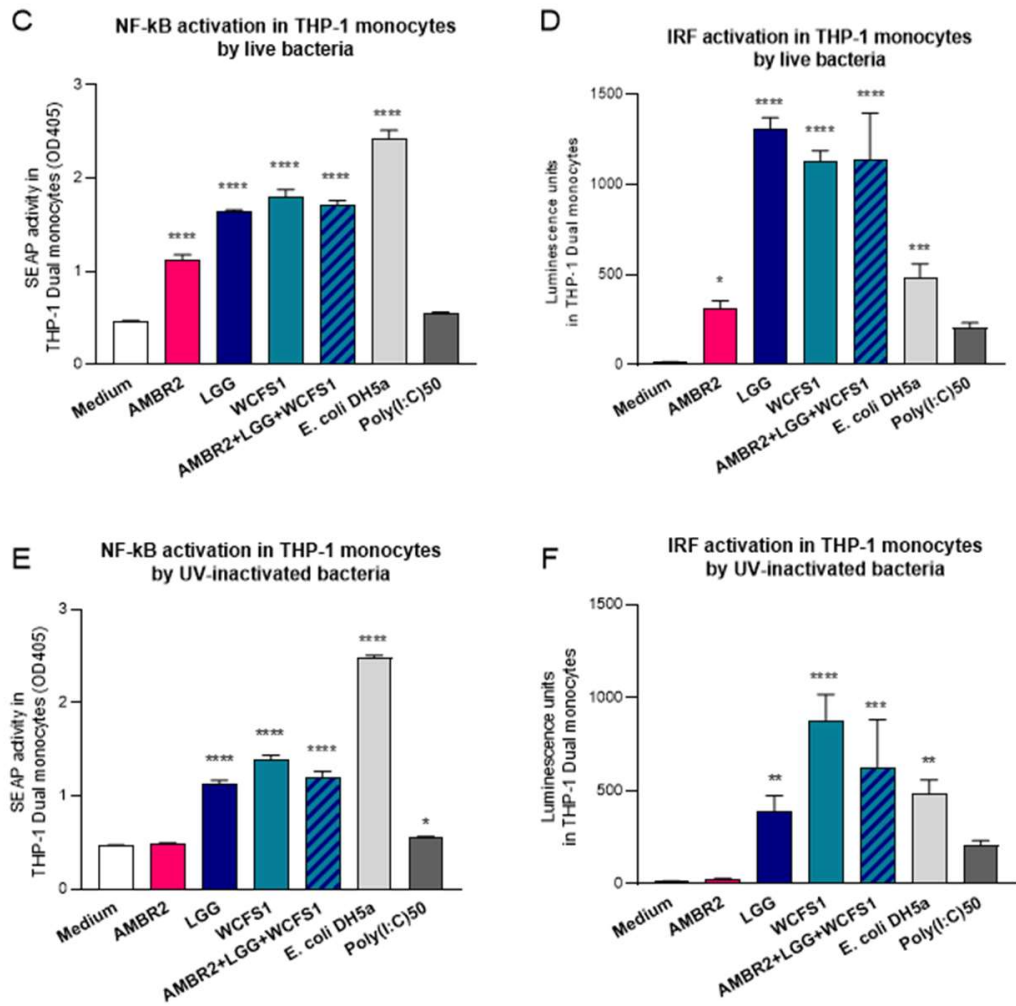

Fig 1 (A) Stimulation of interferon regulatory factors (IRFs) and (B) nuclear factor (NF)-KB by selected 
623 and their combination AMBR2/WCFS1/LGG activate immune pathways involved in antiviral responses. Live $L$.

624 casei AMBR2, L. rhamnosus GG and L. plantarum WCFS1 and their combination induce (C) nuclear factor (NF)-KB

625 and (D) interferon regulatory factors (IRFs) in human THP-1 Dual monocytes upon co-incubation. UV-inactivated

626 L. rhamnosus GG and L. plantarum WCFS1 and their combination with L. casei AMBR2 also induce (E) NF-KB and

627 (F) IRFs in human THP-1 Dual monocytes. The medium condition represents the cells as such and serves as a

628 baseline, while Poly(I:C) at $50 \mu \mathrm{g} / \mathrm{ml}$ with Lipofectamine (Poly(I:C) 50) serves as control IRF inducer and LPS at 20

$629 \mathrm{ng} / \mathrm{ml}$ (LPS20) and LPS-producing E. coli DH5 serve as control NF-KB inducer. Data is depicted as mean \pm SD per

630 condition. ${ }^{*} \mathrm{p}<0.05,{ }^{*} \mathrm{p}<0.01, * * * \mathrm{p}<0.001$ and $* * * * \mathrm{p}<0.0001$ as determined by a One-way ANOVA test followed

631 by Dunnett's multiple comparisons test compared to the medium condition. 
A

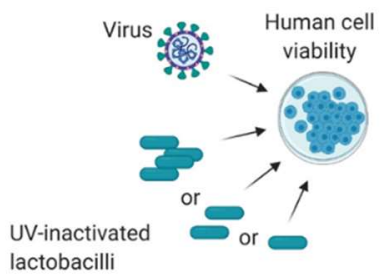

B
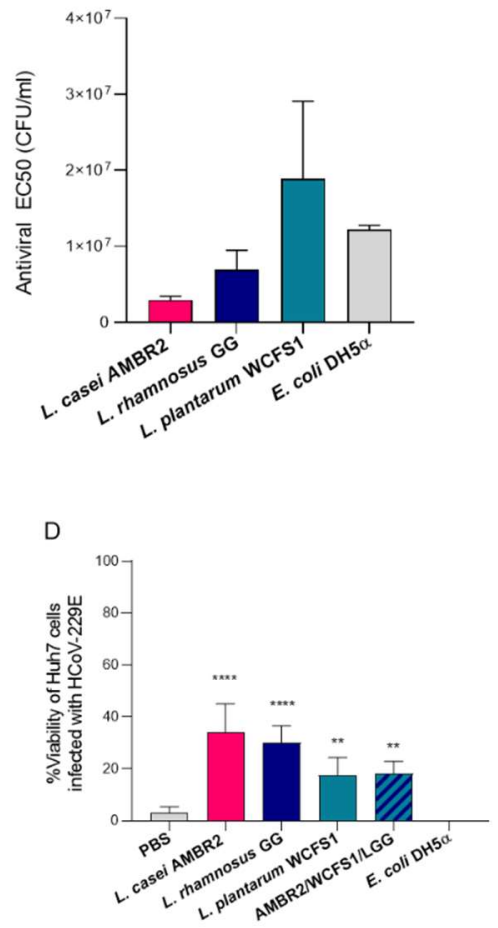

D

G

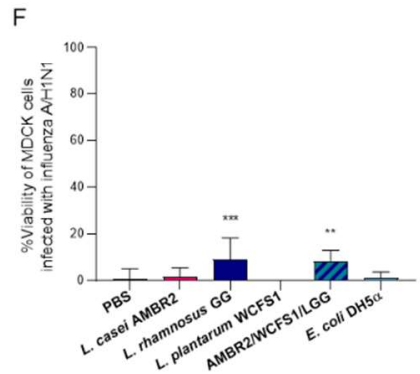

C
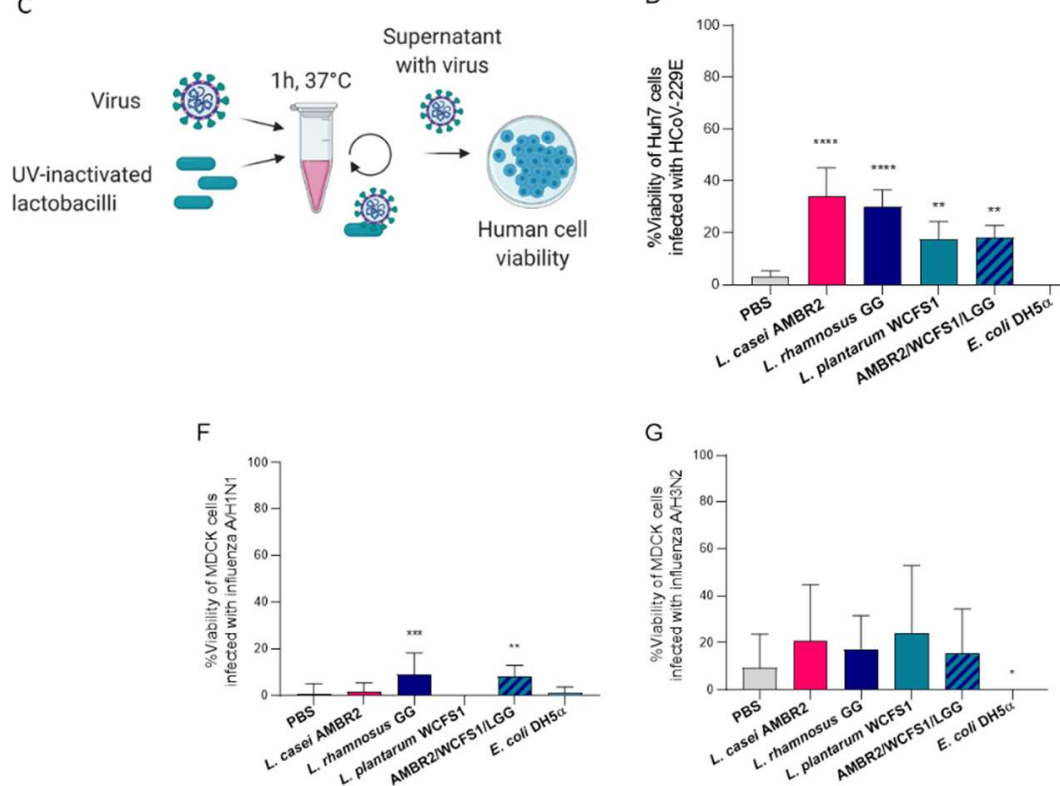

E

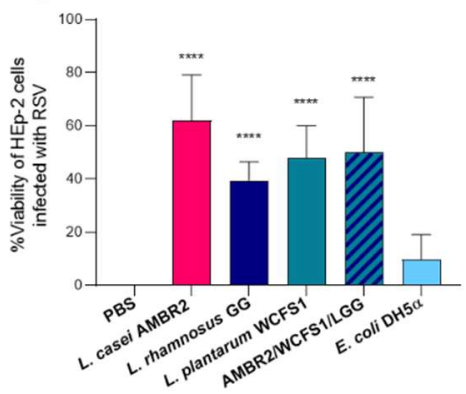

$\mathrm{H}$

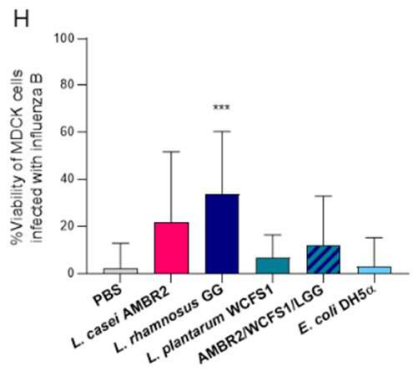

632

633

634

635

636

637

638

639

640

641

642

643

Fig 2 L. casei AMBR2, L. rhamnosus GG, L. plantarum WCFS1 and their combination AMBR2/WCFS1/LGG decrease cytopathogenic effects of HCoV-229E, RSV and influenza A/H1N1, A/H3N2 and B viruses in vitro. $L$. casei AMBR2, L. rhamnosus GG and L. plantarum WCFS1 that were added together with the HCoV-229E virus (A, B) or pre-incubated (C) with HCoV-229E (D), RSV (E), influenza A/H1N1 (F), A/H3N2 (G) or influenza B (FH could inhibit the cytopathic effects induced in human cells. EC50: $50 \%$ Effective concentration producing $50 \%$ inhibition of virus-induced cytopathic effects, as determined by measuring the cell viability with the colorimetric MTS cell viability assay. CFU: colony-forming units. PBS serves as control that does not affect viral infection, $E$. coli $\mathrm{DH} 5 \alpha$ represents a non-probiotic laboratory strain. Data depicted as mean \pm SD per condition. ${ }^{*} p<0.05, * * p<0.01$, $* * * p<0.001$ and $* * * * p<0.0001$ as determined by a One-way ANOVA test followed by Dunnett's multiple comparisons test compared to the medium or PBS conditions. 
A

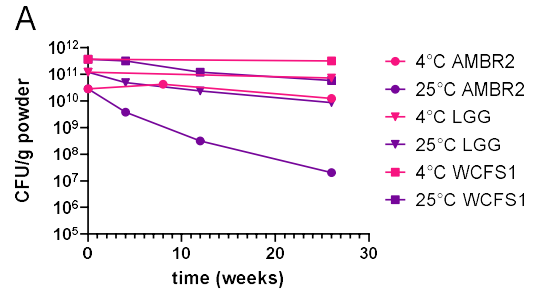

B

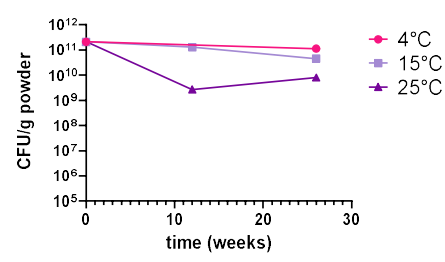

C

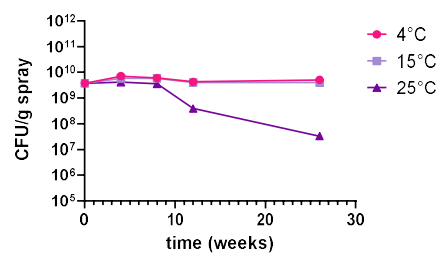

D

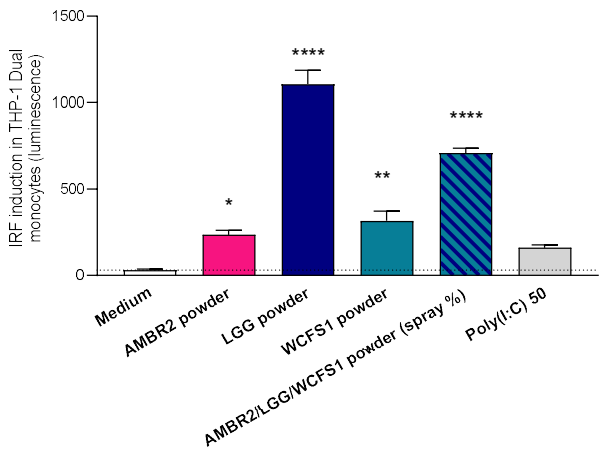

$\mathrm{F}$

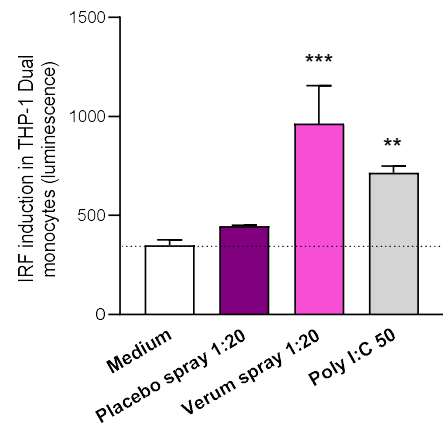

$\mathrm{E}$

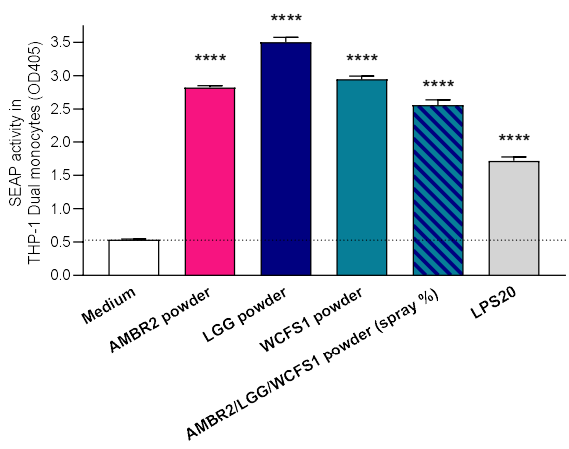

G

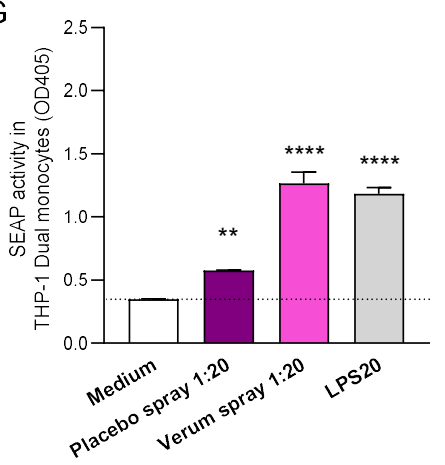

Fig. 3 Viability of individual and combined L. casei AMBR2, L. plantarum WCFS1 and L. rhamnosus GG in (A-B) combination was evaluated at different storage temperatures over time; $4^{\circ} \mathrm{C}, 15^{\circ} \mathrm{C}$ and $25^{\circ} \mathrm{C}$. CFU: colony-forming units. The medium condition represents the cells as such and serves as a baseline, Poly $(\mathrm{I}: \mathrm{C})$ at $50 \mathrm{\mu g} / \mathrm{ml}$ with Lipofectamine (Poly(I:C)50/Lipo) serves as control IRF inducer and LPS at $20 \mathrm{ng} / \mathrm{ml}$ (LPS20) serves as control NF$\mathrm{KB}$ inducer. Data is depicted as mean \pm SD per condition. ${ }^{*} \mathrm{p}<0.05,{ }^{* *} \mathrm{p}<0.01, * * * \mathrm{p}<0.001$ and ${ }^{* * * *} \mathrm{p}<0.0001$ as condition (dotted line). 
A

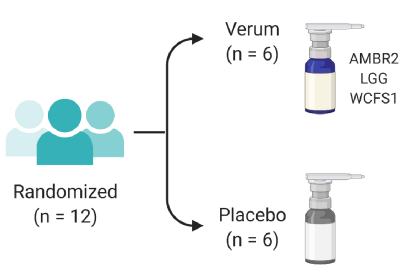

C

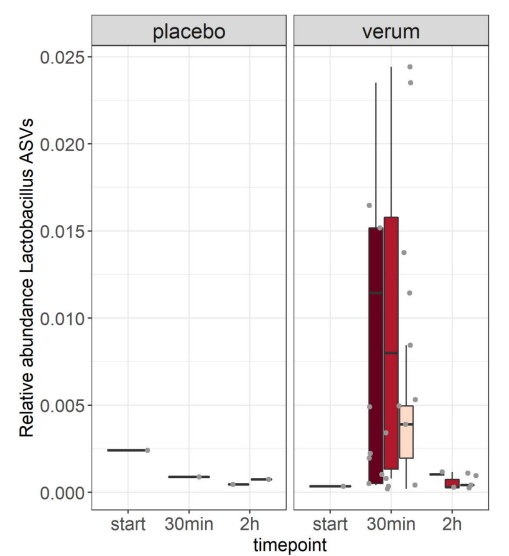

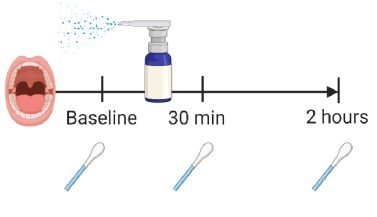

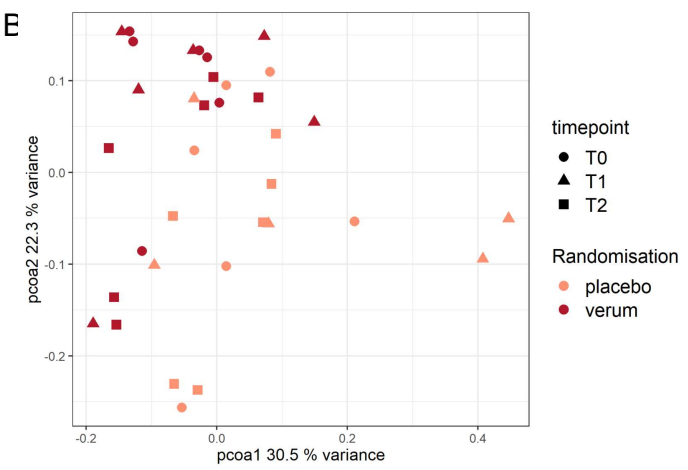

D
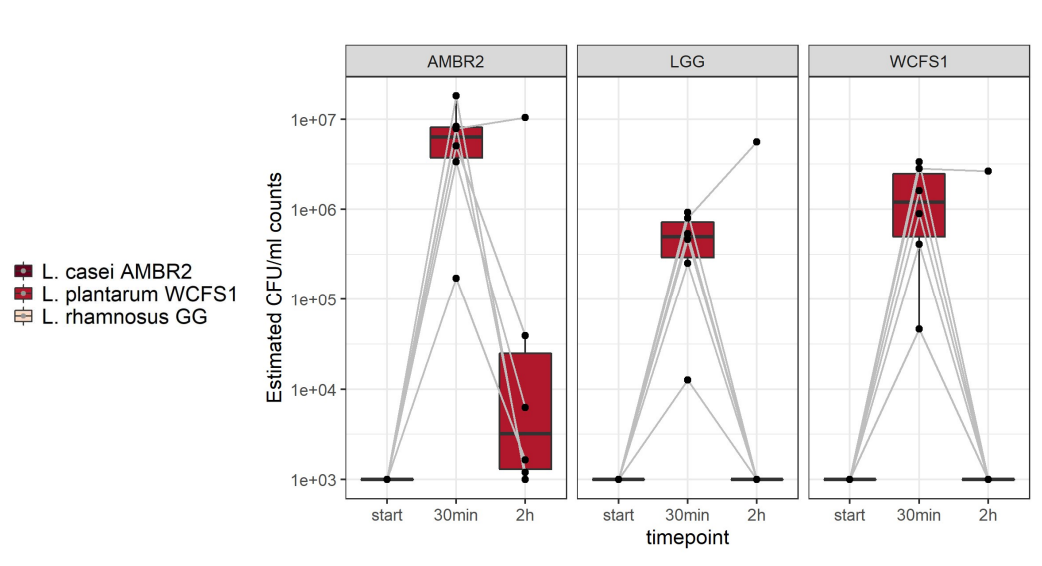

Fig. 4 Evaluation of lactobacilli retention within the throat microbiome of healthy volunteers after spray application. (A) Study set-up; (B) PCOA plot of throat microbiome data based on microbiome analysis via 16S rRNA amplicon sequencing; (C) Relative abundance of the administered lactobacilli in throat swabs based on microbiome analysis via $16 \mathrm{~S}$ rRNA amplicon sequencing;

(D) Relative abundance of the administered lactobacilli in throat swabs based on qPCR analysis. Throat swabs were collected at baseline (TO), and 30 minutes (T1) and 2 hours (T2) after the throat spray was used. The presence of L. casei AMBR2, L. rhamnosus GG, and L. plantarum WCFS1 was evaluated via 16S rRNA amplicon sequencing (relative abundances) in panel C. At 30 minutes and 2 hours, qPCR with species-specific primers was used to estimate the CFU/ml counts in the verum group in panel D. Based on the standard curve, the detection limit was estimated to be at $10^{3} \mathrm{CFU} / \mathrm{ml}$. 
A

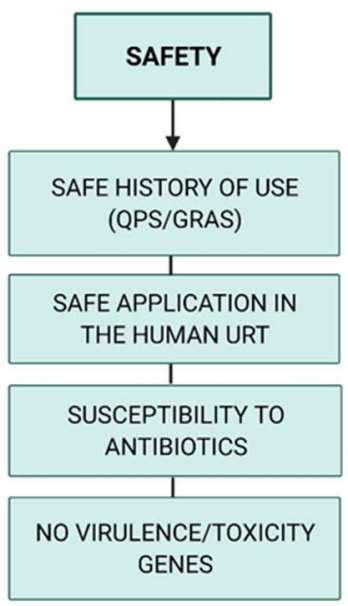

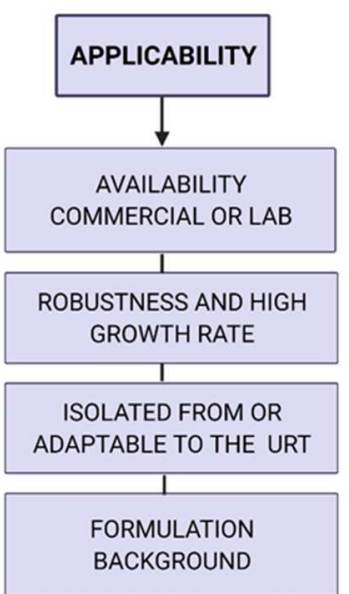

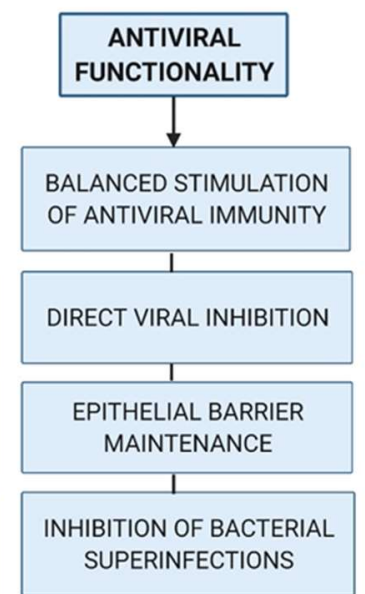

B

ENVISIONED MODE OF ACTION OF THE LACTOBACILLI THROAT SPRAY
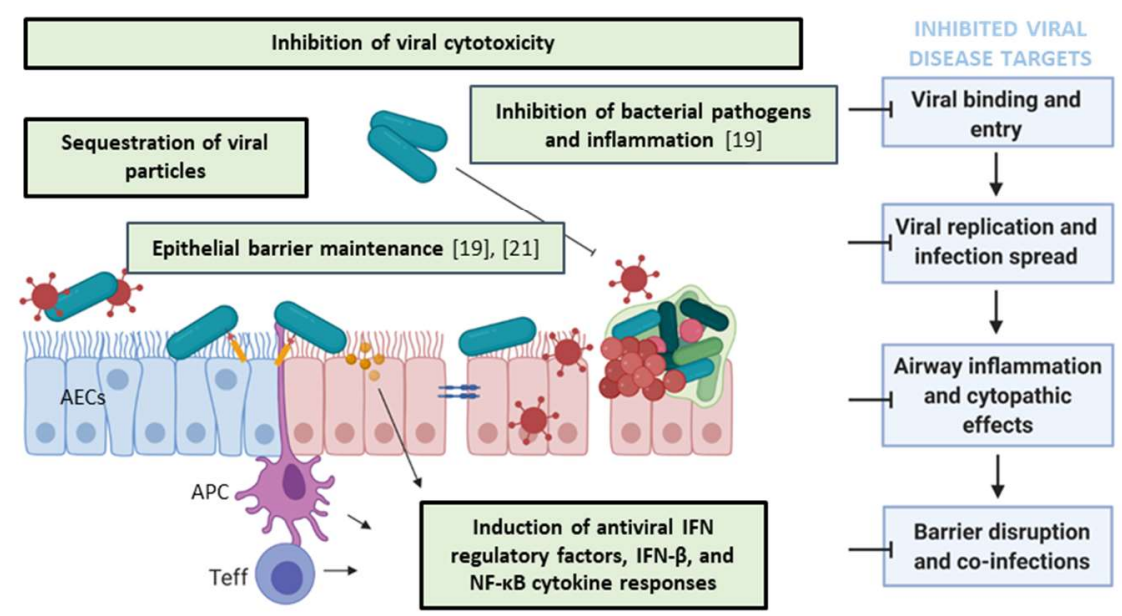

Fig. 5 (A) Rationale for selection of Lactobacillaceae strains for topical application against respiratory viral disease. (B) Documented mechanisms from this and previous studies through which select beneficial lactobacilli formulated as an URT spray can promote the antiviral activity of the URT microbiome. The modes of action explored in this study are shown in bold frames, while available data from previous studies on L. casei AMBR2, L. rhamnosus GG and L. plantarum WCFS1 are indicated in non-bold green boxes [19,21]. IFN: interferon; AECs: airway epithelial cells; APC: antigen-presenting cell; Teff: T effector cell (based on [13]). 